\title{
ESTRATÉGIAS DE MANEJO DO ARRANJO DE PLANTAS VISANDO OTIMIZAR A PRODUTIVIDADE DE GRÃOS DO MILHO
}

\author{
LUÍS SANGOI ${ }^{1}$, AMAURI SCHMITT ${ }^{1}$, MURILO MIGUEL DURLI ${ }^{1}$, \\ LUCIELI SANTINI LEOLATO ${ }^{1}$, ANTONIO EDUARDO COELHO ${ }^{1}$, \\ HUGO FRANCOIS KUNESKI ${ }^{1}$ e VANDER DE LIZ OLIVEIRA ${ }^{1}$
}

\author{
${ }^{1}$ Universidade do Estado de Santa Catarina, Av. Luiz de Camões, 2090, 88.520-000, Lages, SC. \\ E-mail: luis.sangoi@udesc.br,amaurischmitt@gmail.com,murilodurli@gmail.com, \\ lucieli.leolato@gmail.com,coelhoagro7@gmail.com,hugokuneski@outlook.com,vanderdlo@hotmail.com
}

Revista Brasileira de Milho e Sorgo, v.18, n.1, p. 47-60, 2019

\begin{abstract}
RESUMO - Este trabalho foi conduzido objetivando avaliar a resposta do milho ao incremento na densidade de plantas, sob diferentes espaçamentos entre linhas. O experimento foi implantado em Lages-SC, nos dias 20/10/2014 e 21/10/2015. Foram testadas cinco densidades de plantas $\left(3,5,7,9\right.$ e $\left.11 \mathrm{pl} \mathrm{m}^{-2}\right)$ e dois espaçamentos entre linhas (40 cm - reduzido, e $80 \mathrm{~cm}$ - convencional). Avaliaram-se características fenológicas, morfológicas, fisiológicas e a produtividade em kg de grãos ha ${ }^{-1}$ do híbrido $\mathrm{P} 30 \mathrm{R} 50 \mathrm{H}$. Os dados foram analisados estatisticamente pelo teste $\mathrm{F}$, e as médias foram comparadas pelo teste de Tukey e análise de regressão. A produtividade variou de 11.390 a $18.760 \mathrm{~kg} \mathrm{ha}^{-1}$, dependendo do arranjo de plantas testado. Ele aumentou linearmente 923 e $724 \mathrm{~kg} \mathrm{ha}^{-1}$ para cada planta adicionada por $\mathrm{m}^{-2}$ no espaçamento entre linhas de $40 \mathrm{~cm}$ em 2014/2015 e 2015/2016, respectivamente. A elevação na densidade de plantas de 3 para $11 \mathrm{pl} \mathrm{m}^{-2}$ não promoveu assincronia floral, não reduziu a atividade fotossintética da folha índice, nem aumentou a percentagem de plantas acamadas, quando se utilizou o espaçamento entre linhas reduzido. Portanto, a utilização de densidades supraótimas $\left(9\right.$ e $\left.11 \mathrm{pl} \mathrm{m}^{-2}\right)$ e espaçamento entre linhas reduzido $(40 \mathrm{~cm})$ foram estratégias de manejo efetiva para otimizar a produtividade do milho.
\end{abstract}

Palavras-chave: Zea mays, densidade, espaçamento entre linhas, rendimento.

\section{MANAGEMENT OF PLANT ARRANGEMENT TO OPTIMIZE GRAIN PRODUCTIVTY IN MAIZE}

\begin{abstract}
This work was set aiming to evaluate maize response to the increase in plant population at different row spacings. The experiment was conducted in Lages, SC, South of Brazil, on 10/20/2014 and 10/21/2015. Five plant densities $\left(3,5,7,9\right.$ and 11 plants $\left.\mathrm{m}^{-2}\right)$ and two row spacings ( $40 \mathrm{~cm}$ - reduced; $80 \mathrm{~cm}$ - conventional) were tested. Phenological, morphological and physiological traits, productivity ( $\mathrm{kg}$ of grains per ha-1) of the hybrid P30R50 were evaluated. Data were assessed by the F test and means were compared by the Tukey's test and regression analysis. Grain productivity ranged from 11,390 to $18,760 \mathrm{~kg} \mathrm{ha}^{-1}$, depending on the plant arrangement. Linear increase of 923 and $724 \mathrm{~kg} \mathrm{ha}^{-1}$ was observed for each added plant per $\mathrm{m}^{-2}$ at the row spacing of $40 \mathrm{~cm}$, in 2014/2015 and 2015/2016, respectively. The increase in plant density from 3 to 11 plants $\mathrm{m}^{-2}$ did not promote flower asynchrony, did not reduce photosynthetic activity of the index leaf, neither enhanced the percentage of lodged plants when the reduced row spacing was used. Therefore, the use of supra-optimum plant densities $\left(9\right.$ and 11 plants $\left.\mathrm{m}^{-2}\right)$ and reduced row spacing $(40 \mathrm{~cm})$ were efficient strategies of plant arrangement management to optimize maize grain productivity.
\end{abstract}

Keywords: Zea mays, density, row space, productivity. 
$\mathrm{O}$ arranjo das plantas na lavoura tem grande influência sobre o desempenho agronômico do milho. Entre as formas de manipulação do arranjo de plantas, a densidade é que tem maior efeito sobre a produtividade desta Poaceae, pois pequenas alterações na população podem afetar significativamente a produtividade final (Piana et al., 2008). Isto se deve à baixa plasticidade vegetativa e reprodutiva da cultura, decorrente da sua limitada capacidade de perfilhamento, escassa prolificidade, pequena aptidão para alterar a área foliar, bem como ao número e à massa de grãos (Sangoi \& Silva, 2016).

A utilização de baixas densidades de plantas promove subaproveitamento da radiação incidente, diminuindo a produtividade da cultura. Além disto, o uso de densidades subótimas aumenta a competição interespecífica com as plantas daninhas (Balbinot Júnior et al., 2011). O incremento no número de indivíduos por unidade de área e a redução do espaçamento entre linhas são duas formas eficientes de se aumentar a interceptação da radiação incidente pelo dossel, o que pode se refletir em incremento de produtividade (Brachtvogel et al., 2009).

Por outro lado, densidades muito altas podem reduzir a atividade fotossintética da cultura e a eficiência de partição dos fotoassimilados à produção de grãos. Estas alterações fisiológicas promovem aumento da esterilidade feminina e do intervalo entre antese e espigamento, reduzindo o número de grãos por espiga e a produtividade de grãos (Leolato et al., 2017). Densidades supraótimas também fomentam modificações na arquitetura foliar e no desenvolvimento da planta, estimulando a elongação dos entrenós, a produção de colmos mais compridos e de menor diâmetro, aumentando a dominância apical e a altura de inserção de espigas (Liu et al., 2009). Todas estas características favorecem o acamamento e a quebra de colmos antes da colheita. Além disso, o aumento excessivo da densidade pode criar um microclima favorável à infecção por fungos fitopatogênicos por causa da menor penetração de radiação solar nos estratos inferiores da comunidade, da menor circulação de ar, do maior período de deposição de orvalho nas folhas e da maior competição intraespecífica pelos recursos do ambiente (Casa et al., 2007).

A eficiência da elevação da densidade de plantas como estratégia para alavancar a produtividade do milho depende de diversos fatores, tais como disponibilidade hídrica, nível de fertilidade do solo, tipo de híbrido, altitude e latitude da região produtora, época de semeadura, capacidade de investimento em manejo e espaçamento entre linhas (Silva et al., 2010). Ela é maior quando se utilizam híbridos simples, de alto potencial produtivo, cultivados sem restrições edafoclimáticas, em regiões com alta disponibilidade de radiação solar, grande amplitude térmica e com espaçamentos entre linhas reduzidos (Woli et al., 2014). Neste sentido, Piana et al. (2008), Serpa et al. (2012) e Sangoi et al. (2011) constataram que a população de plantas necessária para otimizar a produtividade de grãos dos híbridos contemporâneas de milho é maior quando há adequada disponibilidade de recursos no ambiente e manejo cultural para alto rendimento.

Portanto, o sucesso do adensamento como alternativa de manejo para aumentar a produtividade do milho é afetado por diversas variáveis. Atualmente, a maior parte das empresas que produz sementes de milho no Brasil recomenda densidades de 6 a $8 \mathrm{pl} \mathrm{m}^{-2}$ (Sangoi \& Silva, 2016). Este trabalho foi conduzido com base na hipótese de que a utilização de altas densidades de plantas ( 9 a $11 \mathrm{pl} \mathrm{m}^{-2}$ ) é uma estratégia efetiva para otimizar a produtividade de grãos do milho, principalmente quando combinada com a redução do espaçamento entre linhas. Desta forma, o objetivo foi 
avaliar características fenológicas, morfológicas e fisiológicas, bem como componentes da produtividade de grãos do milho em função do incremento na densidade de plantas, sob diferentes espaçamentos entre linhas.

\section{Material e Métodos}

O experimento foi conduzido em Lages-SC, durante os anos agrícolas de 2014/2015 e 2015/2016. As coordenadas geográficas do local são 27050'35" de latitude sul, 50²9'45" de longitude oeste e altitude de 849 metros. O clima da região é do tipo $\mathrm{Cfb}$, mesotérmico, com verões brandos, temperaturas médias do mês mais quente inferiores a $22{ }^{\circ} \mathrm{C}$ e precipitações pluviais bem distribuídas (Kottek et al., 2006).

O solo da área experimental é classificado como Nitossolo Vermelho Distrófico típico (Santos et al., 2006). A análise de solo, realizada em agosto de 2014, apresentava as seguintes características: $470 \mathrm{~g}$ $\mathrm{kg}^{-1}$ de argila; $\mathrm{pH}$ em água 5,$2 ; 13,5 \mathrm{mg} \mathrm{dm}^{-3}$ de $\mathrm{P}$; $232 \mathrm{mg} \mathrm{dm}^{-3}$ de K; $42 \mathrm{~g} \mathrm{~kg}^{-1}$ de matéria orgânica; 6,1 $\mathrm{cmol}_{\mathrm{c}} \mathrm{dm}^{-3}$ de $\mathrm{Ca} ; 2,6 \mathrm{cmol}_{\mathrm{c}} \mathrm{dm}^{-3}$ de $\mathrm{Mg} ; 0,1 \mathrm{cmol}_{\mathrm{c}}$ $\mathrm{dm}^{-3}$ de Al, e 24,8 $\mathrm{cmol}_{\mathrm{c}} \mathrm{dm}^{-3}$ de CTC. A área experimental estava em rotação com soja (Glycine max L.) e sucessão com aveia-preta (Avena strigosa Schreb).

$\mathrm{O}$ delineamento experimental utilizado foi $\mathrm{o}$ de blocos casualizados dispostos em parcelas subdivididas com quatro repetições. Na parcela principal foram avaliados dois espaçamentos entre linhas: 40 $\mathrm{cm}$ (reduzido) e $80 \mathrm{~cm}$ (convencional). Nas subparcelas foi testado o efeito da densidade, utilizando-se populações de $3,5,7,9,11 \mathrm{pl} \mathrm{m}^{-2}$. Cada sub-parcela foi composta por quatro linhas, com $7 \mathrm{~m}$ de comprimento. Todas as avaliações foram feitas nas duas fileiras centrais, excetuando-se $0,5 \mathrm{~m}$ na extremidade de cada linha.
A adubação utilizada foi determinada seguindo as recomendações da Comissão de Química e Fertilidade do Solo - RS/SC (Manual..., 2004), almejando tetos produtivos de $18.000 \mathrm{~kg} \mathrm{ha}^{-1}$. Foram aplicados no dia da semeadura $30 \mathrm{~kg}$ de $\mathrm{N} \mathrm{ha}^{-1}, 295 \mathrm{~kg} \mathrm{ha}^{-1}$ de $\mathrm{P}_{2} \mathrm{O}_{5}$ e $170 \mathrm{~kg} \mathrm{ha}^{-1}$ de $\mathrm{K}_{2} \mathrm{O}$. A aplicação do $\mathrm{N}$ em cobertura $\left(250 \mathrm{~kg} \mathrm{ha}^{-1}\right)$ foi dividida em três aplicações, feitas quando as plantas se encontravam nos estádios V4, V8 e V12 da escala proposta por Ritchie et al. (1993).

A semeadura foi realizada nos dias 20/10/2014 e 21/10/2015, no sistema de semeadura direta, sobre uma cobertura morta de aveia-preta. Nos dois anos de execução do trabalho utilizou-se o híbrido simples P30R50YH. Depositaram-se três sementes por cova para cada distância pré-determinada na linha em função da densidade e do espaçamento entre linhas. Foram utilizados barbantes marcados com as distâncias pertinentes a cada tratamento para a deposição das sementes. Quando as plantas estavam no estádio V2 da escala de Ritchie et al. (1993), efetuou-se o desbaste para ajustar a população ao valor desejado. As sementes foram tratadas com Tiametoxam e Fipronil nas doses de 140 e 12 g i.a. por $100 \mathrm{~kg}$ de sementes e com Fludioxonil + Metalaxyl na dose de $25+10 \mathrm{~g}$ i.a. por $100 \mathrm{~kg}$ de sementes para o controle preventivo de pragas e doenças na fase inicial do ciclo da cultura.

No dia da semeadura efetuou-se o controle preventivo de plantas daninhas com aplicação em pré-emergência de Atrazina + Metalacloro, nas doses de 1,5+1,15 kg i.a. ha-1 ${ }^{-1}$ Quando as plantas se encontravam em V3, complementou-se o controle das plantas daninhas com a aplicação de Tembotriona na dose de $100 \mathrm{~g}$ i.a. ha-1 ${ }^{-1}$ Além disso, foi realizada uma aplicação de Azixistrobina + Ciproconazol, nas doses de $60+25$ g i.a. ha-1 ${ }^{-1}$ quando o milho estava nos estádios V10 e V18 de desenvolvimento para o controle 
preventivo de doenças. Nos dois anos agrícolas, o ensaio foi irrigado sempre que a tensão de água no solo, medida por tensiômetros, foi inferior a -0,4 Mpa. No primeiro ano agrícola, a precipitação registrada durante o ciclo da cultura foi de $680 \mathrm{~mm}$, e foram feitas três irrigações. No segundo ano, a precipitação total foi de $710 \mathrm{~mm}$, e irrigou-se duas vezes o ensaio. A irrigação foi feita por aspersão, sendo aplicados 30 mm em cada irrigação.

A fenologia da cultura foi avaliada determinando-se a sincronia floral através da duração do subperíodo antese-espigamento. Esta avaliação foi feita computando-se o número de dias entre a deiscência de pólen nos pendões e a exteriorização dos estilo-estigmas nas espigas de pelo menos $75 \%$ das plantas da área útil.

Durante o espigamento, foram marcadas cinco plantas em cada subparcela para avaliações morfológicas e fisiológicas. Estas plantas foram utilizadas para determinar o teor de nitrogênio na folha, o índice de área foliar (IAF), a fotossíntese líquida, a estatura de planta e o diâmetro de colmo. Para avaliação do teor de nitrogênio foliar foram utilizadas amostras da folha índice, correspondente à folha inserida no mesmo nó em que se desenvolveu a espiga, conforme procedimento descrito por Vargas et al. (2012).

A área foliar (AF) e o IAF foram avaliados nos estádios R1 (espigamento) e 30 dias após, quando a cultura estava no estádio R3 (grão leitoso) da escala de Ritchie et al. (1993), seguindo o procedimento descrito por Tollenaar (1992). Para estimativa da AF mediram-se o comprimento $(\mathrm{C})$ e a maior largura (L) de cada folha, e utilizou-se a fórmula $\mathrm{AF}=\mathrm{C}$ x L x 0,75 (Sangoi et al., 2013).

O somatório das áreas de todas as folhas da planta determinou a área foliar por indivíduo. O IAF correspondeu a área foliar por planta dividido pela su- perfície de solo por ela ocupada em cada combinação de densidade e espaçamento entre linhas. A avaliação da fotossíntese líquida foi feita na folha índice, entre 10 horas e 12 horas, durante o estádio R1 da cultura, com o uso do equipamento IRGA (LCpro-SD). A estatura de planta foi estimada em R3, medindose a distância do nível do solo até a extremidade do pendão. $\mathrm{O}$ diâmetro do colmo foi avaliado no dia da colheita, com auxílio de um paquímetro, no primeiro entrenó do colmo expandido acima da superfície do solo (Sangoi et al., 2011).

Antes da colheita foi realizada a contagem do número de espigas planta $^{-1}$ e a percentagem de plantas acamadas, quebradas e estéreis na área útil. Foram consideradas estéreis as plantas que não tinham espigas ou cujas espigas produziram menos de 10 grãos. A colheita foi efetuada nos dias 20/04/2015 e 20/04/2016, quando todas as folhas da planta estavam senescidas e os grãos apresentavam umidade de 18 a $22 \%$. Nas espigas colhidas, foi realizada a avaliação do número de grãos espiga ${ }^{-1} \mathrm{e}$ do número de grãos $\mathrm{m}^{-2}$. Após a trilha foram avaliadas a massa de 1.000 grãos (g) e a produtividade $\left(\mathrm{kg} \mathrm{ha}^{-1}\right)$.

Os dados obtidos foram avaliados estatisticamente pela análise de variância, utilizando o teste F, utilizando o programa SAS (Littell et al., 2006). A análise de variância foi feita de duas formas: individualmente por ano e com os dados conjuntos dos dois anos. Os valores de $\mathrm{F}$ para os efeitos principais e interações foram considerados significativos ao nível de significância de $5 \%(\mathrm{P}<0,05)$. Quando alcançada significância, as médias das densidades de plantas foram comparadas por análise de regressão, testando-se os modelos linear e quadrático. As médias dos espaçamentos entre linhas foram comparadas pelo teste de Tukey. As duas análises de médias foram feitas ao nível de significância de 5\%. 


\section{Resultados e Discussão}

Foram observadas diferenças estatísticas significativas para as variáveis grãos $\mathrm{m}^{-2}$, número de grãos espiga $^{-1}$, massa de 1.000 grãos (g) e produtividade ( $\mathrm{kg}$ $\left.\mathrm{ha}^{-1}\right)$, entre os diferentes anos agrícolas. Por este motivo, estas serão apresentadas individualmente, por estação de crescimento. Os dados referentes às demais variáveis testadas serão descritos conjuntamente, utilizando os valores médios dos dois anos.

Não houve efeito significativo do incremento na densidade de plantas sobre a duração do subperíodo antese-espigamento, nos dois espaçamentos (Figura 1). A cultura do milho, por apresentar distinção espacial e temporal na formação, emissão e maturação de suas inflorescências, tem o intervalo entre a liberação de pólen pelo pendão e a exteriorização dos estilo-estigmas aumentado pelo adensamento, pois esta prática cultural fomenta a natureza protândrica da planta (Sangoi et al., 2013). Os dados fenológicos obtidos no presente trabalho demonstram que houve uma sincronia adequada entre os florescimentos masculino e feminino, pois a duração do subperíodo antese-espigamento foi inferior a 2 dias, mesmo quando se utilizaram densidades elevadas ( 9 e $11 \mathrm{pl} \mathrm{m}^{-2}$ ) e maior espaçamento entre linhas $(80 \mathrm{~cm})$.

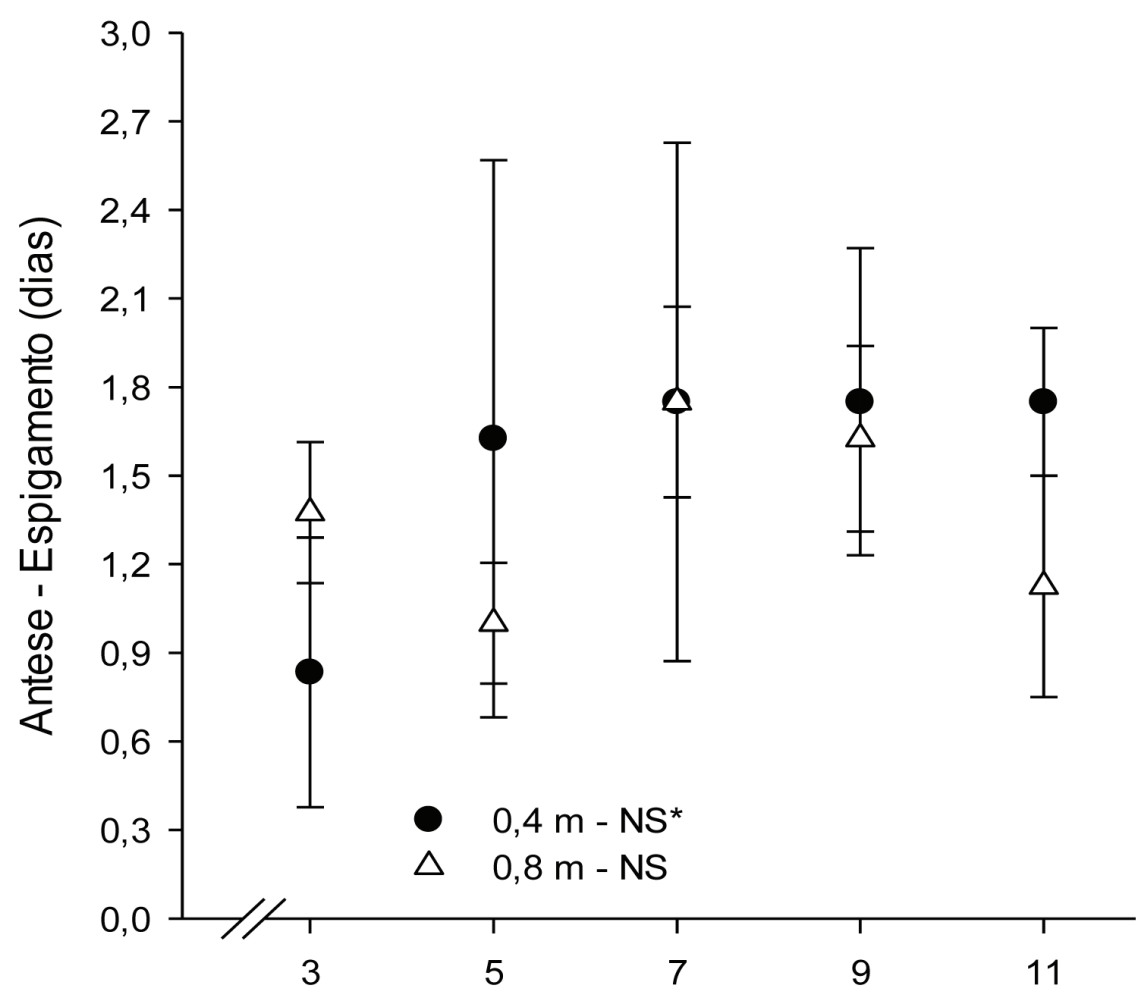

Figura 1. Análise fenológica do subperíodo antese-espigamento do milho em dois espaçamentos entre linhas (0,4 m e 0,8 m) e cinco densidades de plantas (pl m²). Média dos anos agrícolas de 2014/2015 e 2015/2016. Lages-SC. 
O teor médio de nitrogênio da folha índice durante o espigamento foi de 3,9\% e não houve diferença estatística entre os tratamentos (Figura 2A). Plantas com suprimento adequado de nitrogênio apresentam teor de $\mathrm{N}$ foliar oscilando entre 3,7 e 4,2\% (Cantarella \& Marcelino, 2008). Portanto, os resultados obtidos indicam que a quantidade de nitrogênio disponível foi suficiente para suprir as necessidades da planta em todos os tratamentos, mesmo que, segundo Fontoura e Bayer (2009), exista maior competição intraespecífica por nutrientes nas densidades mais altas. Assim, a ausência de efeito negativo da densidade de plantas sobre o teor de $\mathrm{N}$ da folha índice é um indicativo de que o adensamento não comprometeu a absorção de nitrogênio pela cultura.

A fotossíntese líquida na folha índice no espigamento apresentou uma grande variação nos valores observados, os quais oscilaram de 3 a $25 \mathrm{mmol} \mathrm{m}^{-2}$ $\mathrm{s}^{-1}$ de $\mathrm{CO}_{2}$ fixado (Figura 2B). A fixação de carbono através da fotossíntese reduziu linearmente com o aumento na densidade de 3 para $11 \mathrm{pl} \mathrm{m}^{-2}$ no espaçamento entre linhas de $80 \mathrm{~cm}$. Por outro lado, não houve efeito da densidade de plantas sobre esta variável no espaçamento entre linhas de $40 \mathrm{~cm}$. Isto indica maior comprometimento da atividade fotossintética com o adensamento no espaçamento de $80 \mathrm{~cm}$ do que no de $40 \mathrm{~cm}$. Provavelmente este comportamento está associado à maior distância entre plantas na linha obtida com a redução do espaçamento entre linhas. O melhor arranjo espacial obtido no espaçamento de $40 \mathrm{~cm}$ possivelmente permitiu melhor penetração de radiação solar nos diferentes estratos do dossel, atenuando a competição por luminosidade, comportamento também observado por Liu et al. (2009), Strieder et al. (2008) e Boiago et al. (2017).

O IAF no espigamento aumentou linearmente com o incremento na densidade de planta nos dois espaçamentos entre linhas (Figura 2C). O mesmo comportamento foi verificado na avaliação feita 30 dias após (Figura 2D), quando os grãos estavam no estádio R3 (grão leitoso) da escala de Ritchie et al. (1993). Mesmo nas densidades mais altas, o IAF foi maior do que 5 em R3. Desta forma, todos os valores encontrados 30 dias após o espigamento foram superiores ao IAF crítico necessário para interceptar $95 \%$ da radiação incidente, que, segundo Robles et al. (2012), situa-se entre 4 e 5. Portanto, o adensamento não fomentou uma senescência foliar prematura. Esta é uma característica importante que os híbridos contemporâneos apresentam e que lhes permite melhor adaptação a ambientes de elevada competição intraespecífica (Hammer et al., 2009; Sangoi et al., 2013).

A estatura de planta do híbrido P30R50 reportada por Sangoi et al. (2013) oscilou entre 290 e $302 \mathrm{~cm}$. No presente ensaio, ela variou de 305 a $310 \mathrm{~cm}$ e não foi afetada pelo adensamento quando o milho foi cultivado no espaçamento entre linhas de $40 \mathrm{~cm}$. Houve redução linear de 309 para $283 \mathrm{~cm}$ com o incremento da densidade no espaçamento de $80 \mathrm{~cm}$ (Figura 3A). Segundo Leolato et al. (2017), o adensamento aumenta a competição intraespecífica por radiação solar, estimulando a dominância apical e o estiolamento das plantas. O decréscimo na estatura decorrente do adensamento no espaçamento entre linhas de $80 \mathrm{~cm}$ possivelmente está relacionado à redução na fotossíntese líquida da folha índice registrada neste arranjo de plantas (Figura 2B).

No momento da colheita, foi constatado que o aumento na densidade de plantas, nos diferentes espaçamentos entre linhas (40 e $80 \mathrm{~cm}$ ) não provocou acamamento nas plantas de milho (Figura 3B). Já a percentagem de colmos quebrados aumentou linearmente com o adensamento no espaçamento de $80 \mathrm{~cm}$ en- 
A
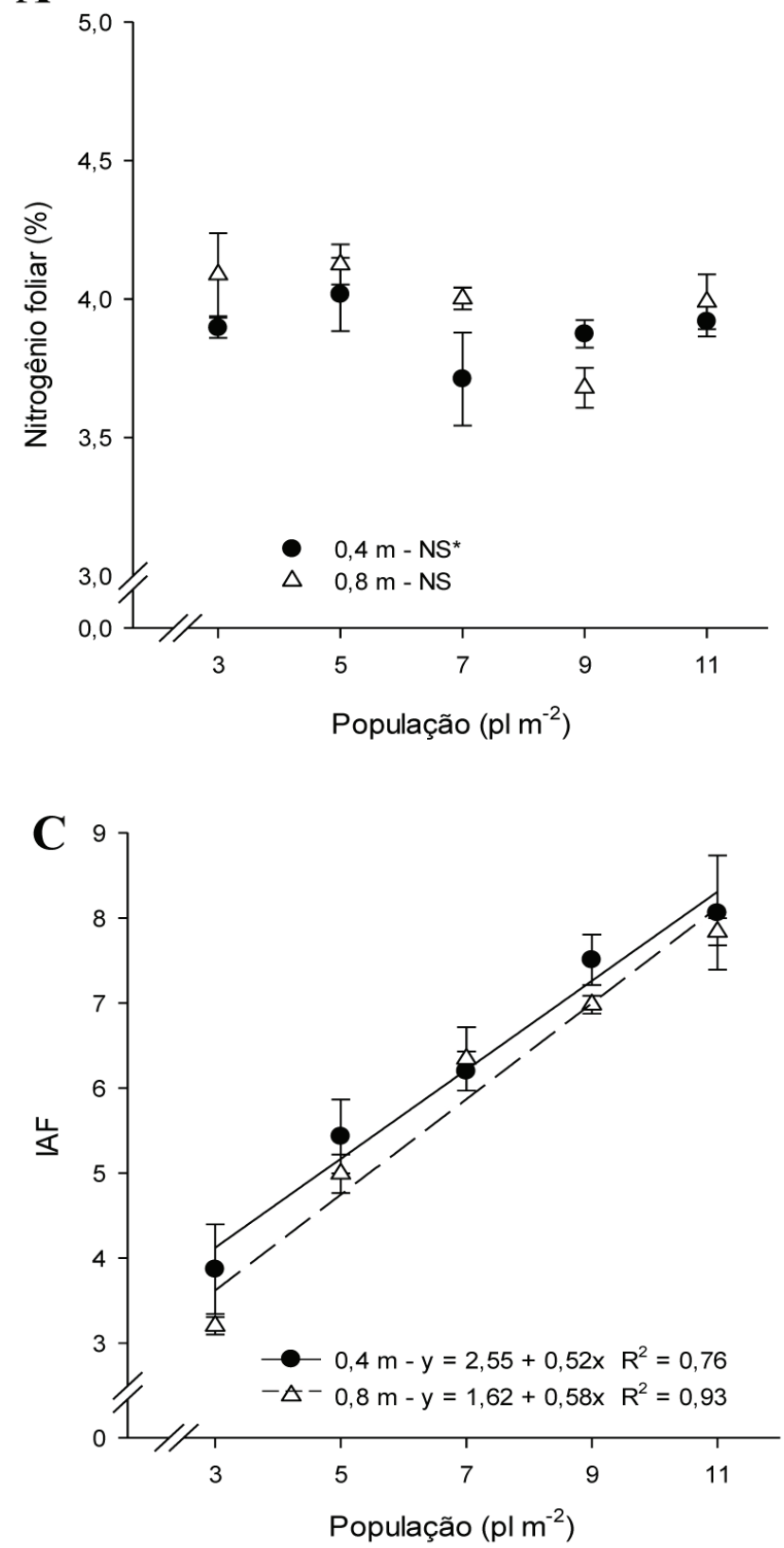
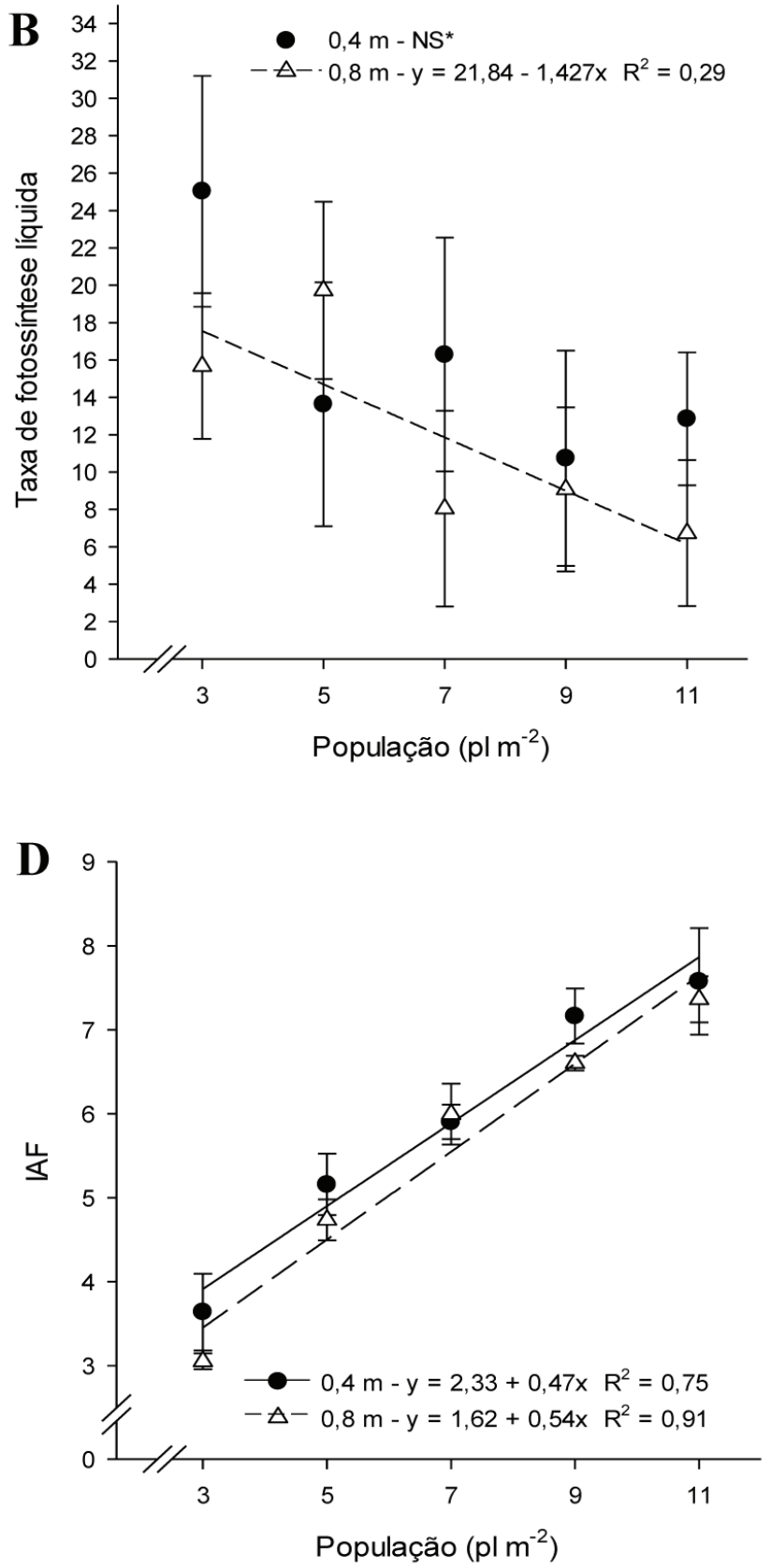

Figura 2. Análise da fisiologia: teor de nitrogênio da folha índice (A), fotossíntese líquida na folha índice (B), índice de área foliar no espigamento (C), índice de área foliar na fase de grão leitoso (D) do milho em dois espaçamentos entre linhas $(0,4 \mathrm{~m}$ e $0,8 \mathrm{~m})$ e cinco densidades de plantas $\left(\mathrm{pl} \mathrm{m}^{-2}\right)$. Média dos anos agrícolas de 2014/2015 e 2015/2016. Lages-SC. 
tre linhas (Figura 3C). O incremento na percentagem de colmos quebrados registrado quando se aumentou a população de plantas no espaçamento de $80 \mathrm{~cm}$ está relacionado com as maiores taxas de decréscimo do diâmetro de colmo observadas para esse espaçamento com o adensamento (Figura 3D). Segundo Strieder et al. (2007), nos espaçamentos entre linhas reduzidos, as plantas apresentam uma melhor estrutura de colmo para suportar a espiga nas densidades mais altas. Isto se deve à maior penetração da radiação solar nos estratos inferiores do dossel, decorrente da melhor distribuição espacial das plantas, que permite ao colmo acumular maior quantidade de eservas nos seus entrenós inferiores. Independentemente dos tratamentos utilizados, a sustentabilidade do colmo na colheita foi satisfatória, pois a percentagem de colmos quebrados foi menor do que $4 \%$.

Nos dois anos de condução do trabalho, a média do número de espigas planta ${ }^{-1}$ foi sempre próxima ou superior a 1 (Figura 4A). A percentagem de plantas estéreis foi menor do que $4 \%$, mesmo nas densidades mais altas (Figura 4B). Além disso, as espigas produzidas apresentaram média de mais de 430 grãos (Figura 4C, D). Um dos principais problemas apresentados pelo milho quando se utilizam densidades muito altas é o aumento da dominância apical, o qual favorece a esterilidade feminina (Brachtvogel et al., 2009). Em estandes supraótimos, a planta favorece o desenvolvimento do pendão em detrimento das espigas. Este comportamento protândrico aumenta a defasagem entre antese e espigamento, reduzindo o número de óvulos fertilizados (Leolato et al., 2017). Os dados da Figura 4 demonstram que, em ambientes irrigados e com alta fertilidade, a natureza protândrica do milho é minimizada, reduzindo a esterilidade feminina e possibilitando fertilização adequada dos óvulos da espiga.
O número de grãos produzidos por área é o principal componente que impacta a produtividade final do milho (Boiago et al., 2017). A baixa esterilidade feminina (Figura 4 B) e o alto número de grãos produzidos por espiga (Figura 4C, D) possibilitaram a produção de mais de 4.500 grãos por $\mathrm{m}^{-2}$ com estandes adensados e espaçamento entre linhas reduzido (Figura 5A, B). Esta mesma tendência foi constatada por Piana et al. (2008) e Serpa et al. (2012), em trabalhos conduzidos na Depressão Central do Rio Grande do Sul.

A massa de 1.000 grãos superou $330 \mathrm{~g}$ em todos os tratamentos (Figura 5C, D). Um dos inconvenientes do adensamento é reduzir a penetração de radiação solar no interior do dossel, acelerando a senescência foliar, reduzindo a duração do período de enchimento de grãos e fomentando a produção de grãos leves, com massa de 1.000 grãos inferior a 300 g (Sangoi \& Silva, 2016). Este comportamento não foi registrado no trabalho, pois mesmo nas densidades mais altas o IAF da cultura se manteve acima do valor crítico em R3 (Figura 2D).

A combinação dos componentes do rendimento propiciou a obtenção de produtividade de grãos superiores a $18.000 \mathrm{~kg} \mathrm{ha}^{-1}$ quando se combinou alta densidade (11 plantas $\mathrm{m}^{-2}$ ) com espaçamento entre linhas reduzido $(40 \mathrm{~cm})$. Nos dois anos agrícolas, a interação entre densidade de plantas e espaçamento entre linhas interferiu significativamente na produtividade de grãos da cultura. Os valores oscilaram entre 11.390 e $18.760 \mathrm{~kg} \mathrm{ha}^{-1}$ no primeiro ano e entre 11.920 e $18.560 \mathrm{~kg} \mathrm{ha}^{-1}$ no segundo ano agrícola (Figura 5E, F). A resposta da produtividade ao adensamento foi diferente nos dois espaçamentos entre linhas. Tanto em 2014/2015 quanto em 2015/2016, a produtividade de grãos aumentou linearmente com o incremento na densidade de 3 para 11 plantas $\mathrm{m}^{-2}$ no espaçamento entre linhas de $40 \mathrm{~cm}$. As taxas de aumento foram de 

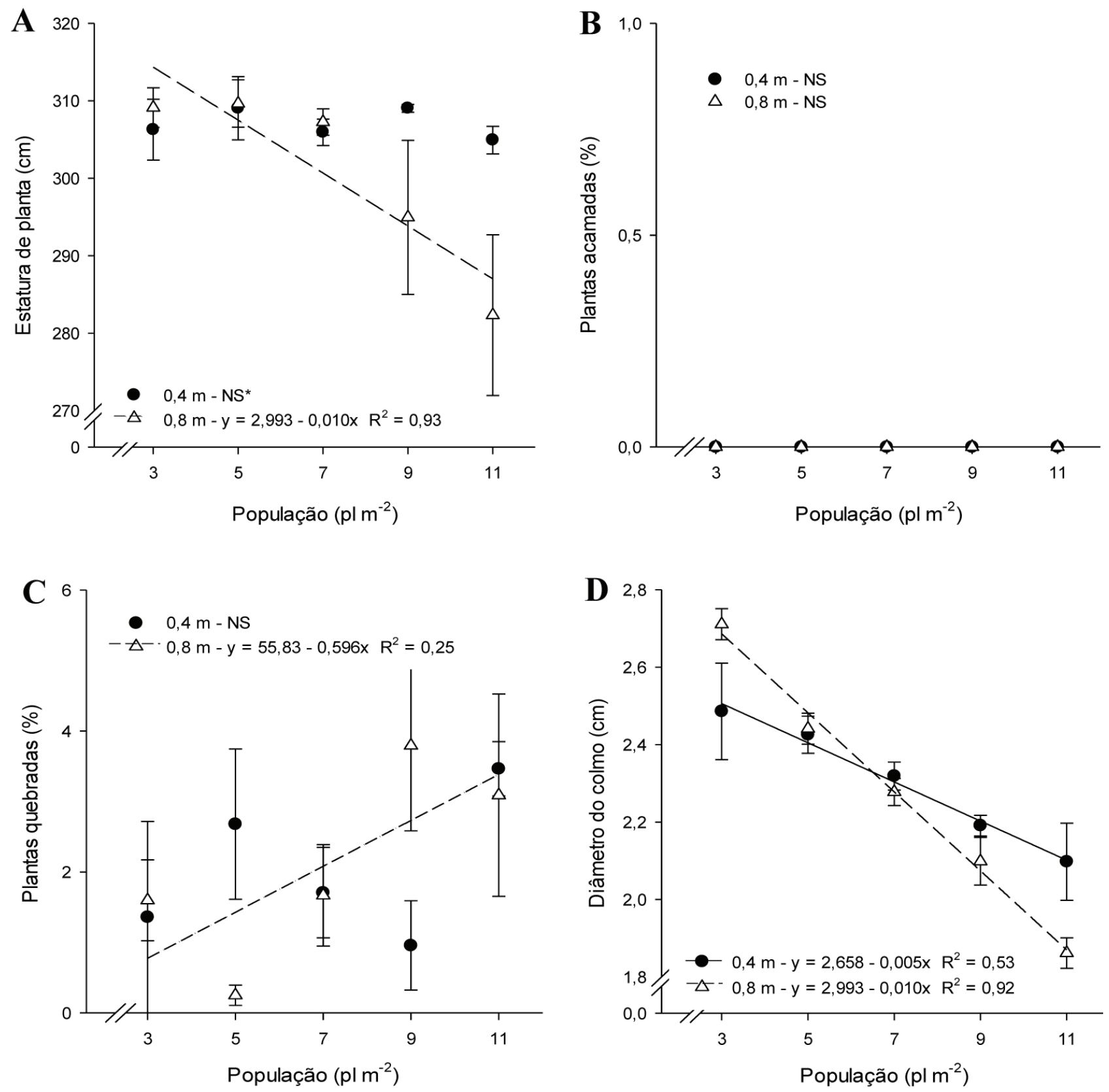

Figura 3. Análise da morfologia: estatura de planta (A), percentagem de plantas acamadas (B), percentagem de plantas quebradas (C) e diâmetro de colmo (D) do milho em dois espaçamentos entre linhas $(0,4 \mathrm{~m}$ e $0,8 \mathrm{~m})$ e cinco densidades de plantas ( $\mathrm{pl} \mathrm{m}^{-2}$ ). Média dos anos agrícolas de 2014/2015 e 2015/2016. Lages-SC. 

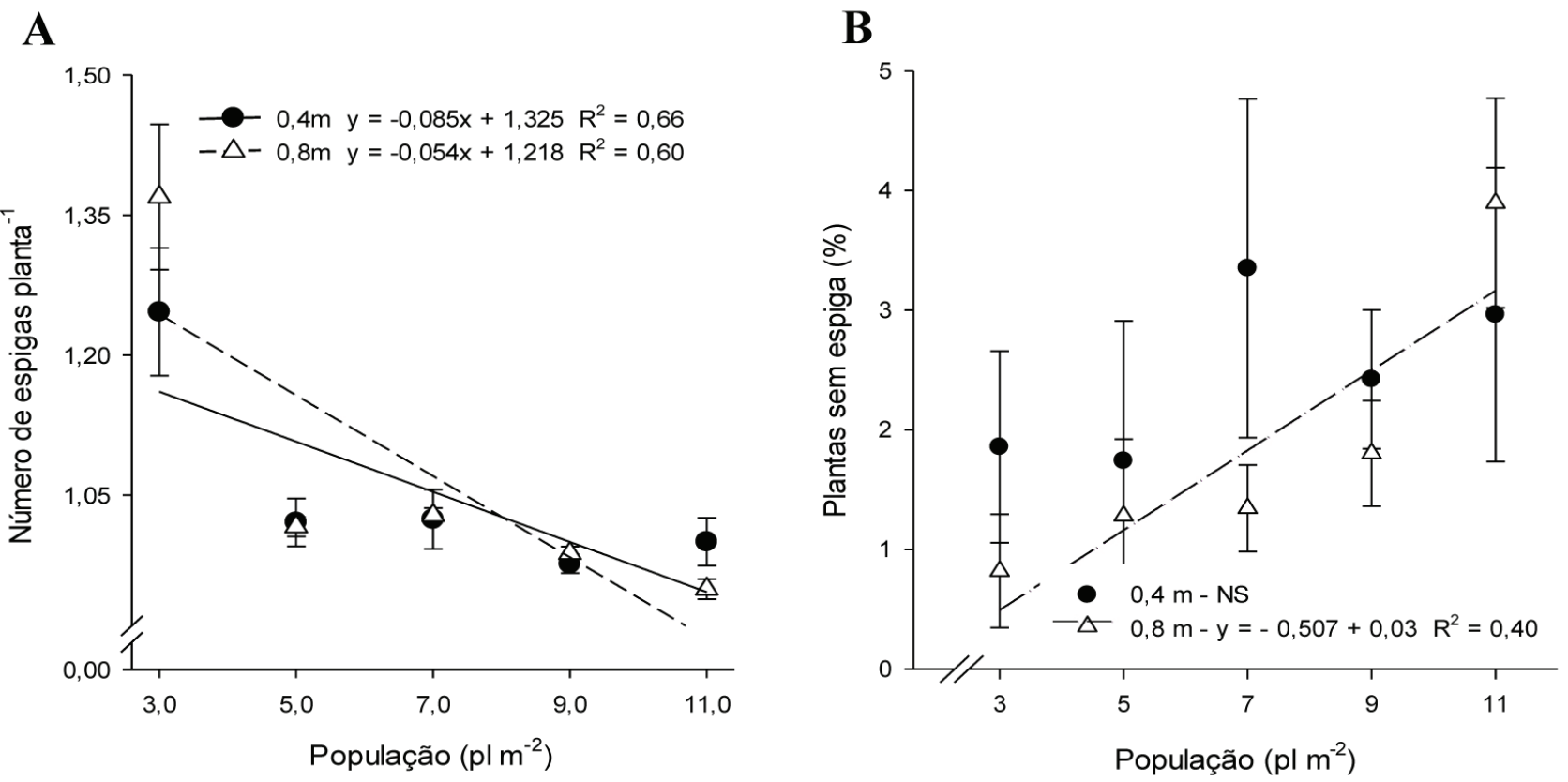

C

\section{D}
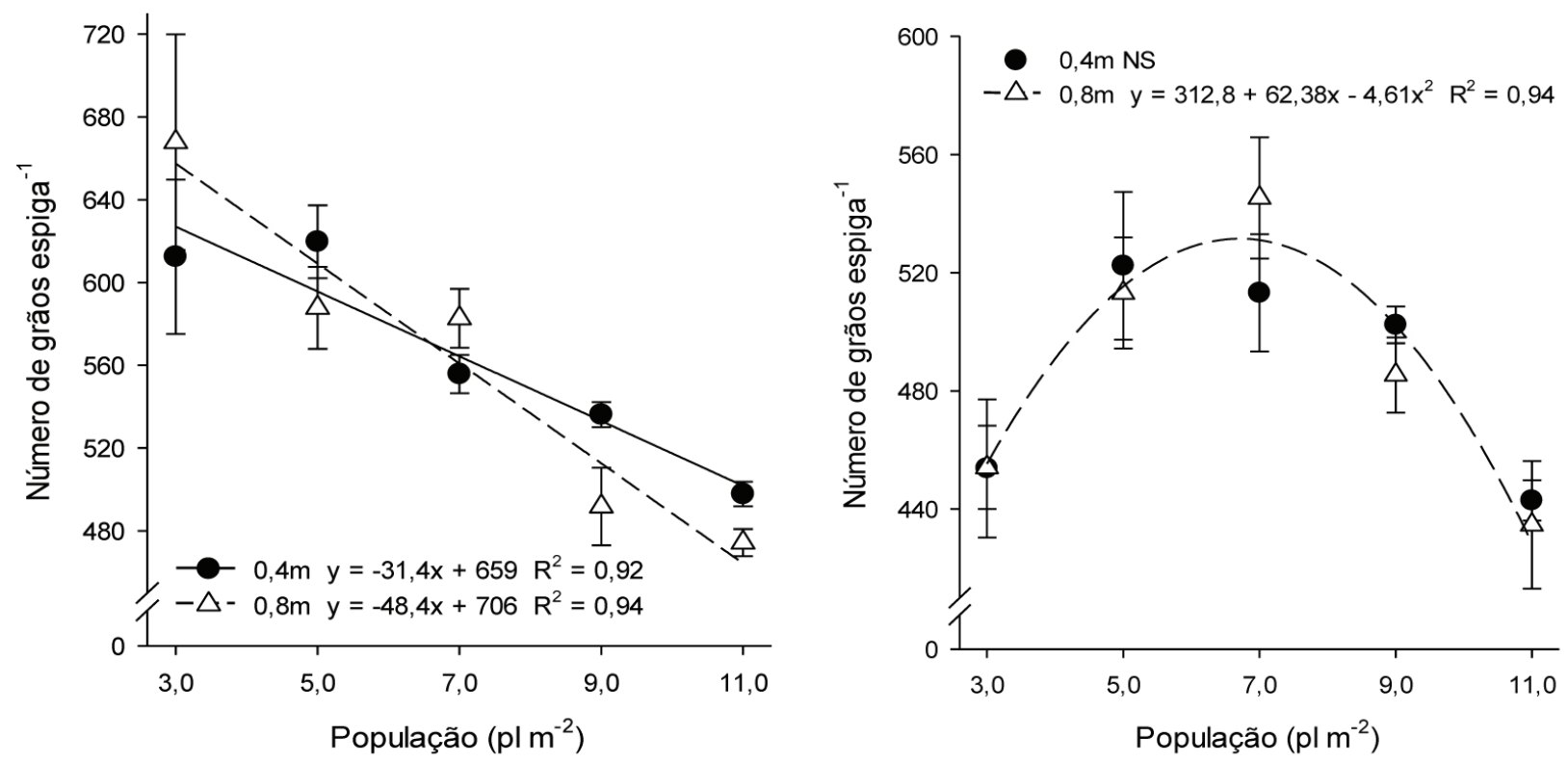

Figura 4. Análise dos componentes de rendimento: número de espigas planta-1 $(\mathrm{A})$, percentagem de plantas sem espiga (B), na média dos anos agrícolas de 2014/2015 e 2015/2016, e número de grãos por espiga ${ }^{-1} \mathrm{em}^{-}$ 2014/2015 (C) e 2015/2016 (D) do milho em dois espaçamentos entre linhas (0,4 m e 0,8 m) e cinco densidades

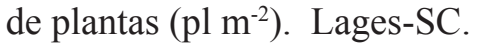



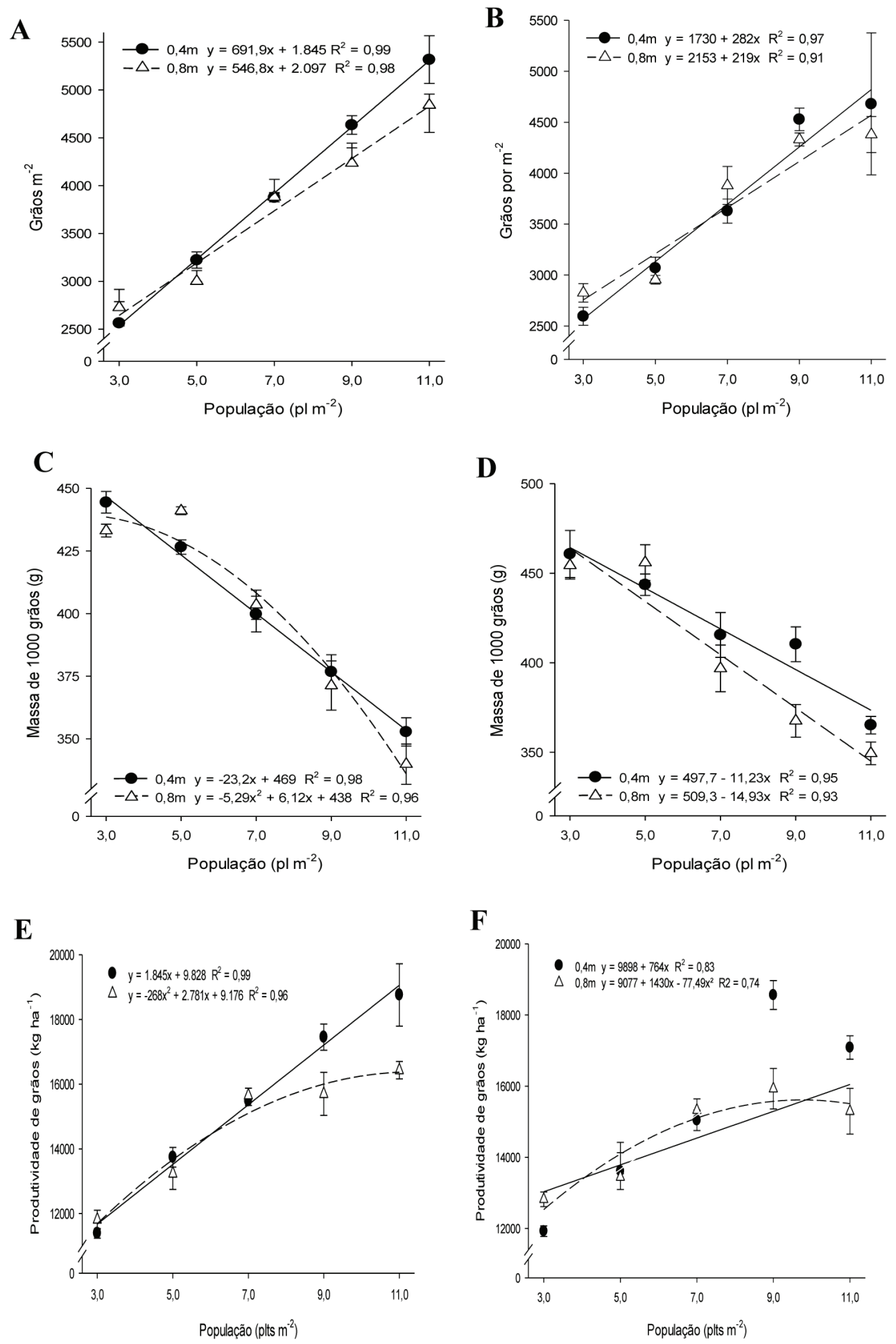

Figura 5. Análise dos componentes de rendimento: número de grãos $\mathrm{m}^{-2}(\mathrm{~A}, \mathrm{~B})$, massa de 1.000 grãos $(\mathrm{C}$, D) e produtividade de grãos (E, F). Média nos anos agrícolas de 2014/2015 (A, C, E) e 2015/2016 (B, D, F). Lages-SC. 
$923(2014 / 2015)$ e $764 \mathrm{~kg} \mathrm{ha}^{-1}(2015 / 2016)$ para cada planta adicionada por $\mathrm{m}^{-2}$. Por outro lado, a produtividade de grãos aumentou de forma quadrática no espaçamento entre linhas de $80 \mathrm{~cm}$, sendo as máximas produtividades alcançadas nas densidades de 11,2 (2014/2015) e 9,2 (2015/2016) pl m².

Atualmente, as recomendações de densidade para condições favoráveis de manejo, clima e solo oscilam entre 6,5 e 8,0 plantas $\mathrm{m}^{-2}$ (Sangoi \& Silva, 2016). Os resultados obtidos corroboram as observações feitas por Piana et al. (2008), Serpa et al. (2012), Haegele et al. (2014), Mansfield et al. (2014) e Boiago et al. (2017), mostrando que a combinação entre alta densidade e espaçamentos entre linhas reduzidos é estratégia de manejo efetiva para maximizar a produtividade do milho quando se utilizam híbridos simples de alto potencial produtivo, cultivados em ambientes sem restrições hídricas e edáficas. Os resultados obtidos no presente trabalho mostraram que nenhum dos inconvenientes fenológicos, morfológicos e fisiológicos advindos do adensamento foi relevante para comprometer o desempenho agronômico da cultura quando o uso de altas densidades foi associado à redução do espaçamento entre linhas. O comportamento da produtividade observado nos dois anos de condução do experimento demonstrou que, apesar de o incremento na densidade melhorar a produtividade de grãos, ele não é uma prática de manejo que deve ser utilizada isoladamente, mas sim conjugada a outras formas de manipulação do arranjo para melhor distribuição das plantas na área, como a redução no espaçamento entre linhas.

\section{Conclusões}

1. O incremento na densidade de 3 para $11 \mathrm{pl}$ $\mathrm{m}^{-2}$ e a redução do espaçamento entre linhas de 80 para $40 \mathrm{~cm}$ foram estratégias eficientes para otimizar a produtividade de grãos do milho nas condições em que o experimento foi conduzido.

2. Existe potencial para alcançar produtividades de milho superiores a $18.000 \mathrm{~kg} \mathrm{ha}^{-1}$ quando combinadas densidades supraótimas de 9 a $11 \mathrm{pl} \mathrm{m}^{-2} \mathrm{e}$ espaçamentos entre linhas reduzidos de $40 \mathrm{~cm}$.

\section{Agradecimentos}

Ao $\mathrm{CNPq}$, pela bolsa de produtividade em pesquisa ao primeiro autor e pelo apoio financeiro ao projeto (Edital Universal 014/2011). À Dupont do Brasil S.A - Divisão Pioneer sementes, pelo apoio financeiro à execução do trabalho. À Capes, pela concessão de bolsa de estudos ao segundo autor. À FAPESC/PAP/UDESC pelo apoio financeiro à execução do trabalho.

\section{Referências}

BALBINOT JÚNIOR, A. A.; TREZZI, M. M.; VOGT, G. A. Integração de práticas para o manejo de plantas daninhas na cultura do milho. Scientia Agraria, Curitiba, v. 12, n. 2, p. 81-87, 2011. DOI: 10.5380/rsa.v12i2.33724.

BOIAGO, R. G. F. S.; MATEUS, R. P. G.; SCHUELTER, R. R. B.; SILVA, G. J.; SCHUSTER, I. Combinação de espaçamento entrelinhas e densidade populacional no aumento da produtividade em milho. Revista Brasileira de Milho e Sorgo, Sete Lagoas, v. 16, n. 3, p. 440-448, 2017. DOI: 10.18512/1980-6477/rbms.v16n3p440-448.

BRACHTVOGEL, E. L.; PEREIRA, F. R. S.; CRUZ, S. C. S.; BICUDO, S. J. Densidades populacionais de milho em arranjos espaciais convencional e equidistante entre plantas. Ciência Rural, Santa Maria, v. 39, n. 8, p. 23342339, 2009. DOI: 10.1590/S0103-84782009005000193.

CASA, R. T.; MOREIRA, E. N.; BOGO, A.; SANGOI, L. Incidência de podridões do colmo, grãos ardidos e 
rendimento de grãos em híbridos de milho submetidos ao aumento na densidade de plantas. Summa Phytopathologica, Botucatu, v. 33, n. 4, p. 353-357, 2007. DOI: $10.1590 / \mathrm{S} 0100-54052007000400006$.

CANTARELLA, H.; MARCELINO, R. Fontes alternativas de nitrogênio para a cultura do milho. Informações Agronômicas, Piracicaba, n. 122, p.12-14, 2008.

FONTOURA, S. M. V.; BAYER, C. Adubação nitrogenada para alto rendimento de milho em plantio direto na região centro-sul do Paraná. Revista Brasileira de Ciência do Solo, Viçosa, MG, v. 33, n. 6, p. 1721-1732, 2009.

DOI: $10.1590 / \mathrm{S} 0100-06832009000600021$.

HAEGELE, J. W.; BECKER, R. J.; HENNINGER, A. S.; BELOW, F. E. Row arrangement, phosphorus fertility and hybrid contributions to managing increased plant density of maize. Agronomy Journal, Madison, v. 106, n. 5, p. 1838-1846, 2014. DOI: 10.2134/agronj2013.0382.

HAMMER, G. L.; DONG, Z.; MCLEAN, G.; DOHERTY, C.; MESSINA, C.; SCHUSSLER, J., ZINSELMEIER, C.; PASZKIEWICZ, S.; COOPER, M. Can changes in canopy and/or root system architecture explain historical maize yield trends in the U.S. Corn Belt? Crop Science, Madison, v. 49, n. 1, p. 299-312, 2009.

DOI: 10.2135/cropsci2008.03.0152.

KOTTEK, M.; GRIESER, J.; BECK, C.; RUDOLF, B.; RUBEL, F. World Map of the Köppen-Geiger climate classification updated. Meteorologische Zeitschrift, v. 15, n. 3, p. 259-263, 2006.

DOI: $10.1127 / 0941-2948 / 2006 / 0130$.

LEOLATO, L. S.; SANGOI, L.; DURLI, M. M.; PANISON, F.; VOSS, R. Regulador de crescimento e resposta do milho ao aumento na densidade de plantas. Pesquisa Agropecuária Brasileira, Brasília, DF, v. 52, n. 11, p. 997-1015, 2017.

DOI: 10.1590/S0100-204X2017001100005.

LITTELL, R. C.; MILLIKEN, G. A.; STROUP, W. W.; WOLFINGER, R. D.; SCHABENBERGER. O. SAS Mixed Models. 2. ed. Cary: SAS Institute, 2006. 813 p.
LIU, J. G.; MAHONEY, K. J.; SIKKEMA, P. H.; SWANTON, C. J. The importance of light quality in cropweed competition. Weed Research, Oxford, v. 49, n.2, p. 217-224, 2009.

DOI: $10.1111 /$ j.1365-3180.2008.00687.x.

MANSFIELD, B. D.; MUMM R. H. Survey of plant density tolerance in U.S. maize germplasm. Crop Science, Madison, v. 54, n. 1, p. 157-173, 2014.

DOI: 10.2135/cropsci2013.04.0252.

MANUAL de adubação e de calagem para os Estados do Rio Grande do Sul e Santa Catarina. 10 ed. Porto Alegre: Sociedade Brasileira de Ciência do Solo, 2004. 400 p.

PIANA, A. T.; SILVA, P. R. F.; BREDEMEIER, C.; SANGOI, L.; VIEIRA, V. M.; SERPA, M. S; JANDREY, D. B. Densidade de plantas de milho híbrido em semeadura precoce no Rio Grande do Sul. Ciência Rural, Santa Maria, v. 38, n. 9, p. 2608-2612, 2008.

DOI: $10.1590 / \mathrm{S} 0103-84782008005000023$.

RITCHIE, S. W.; HANWAY, J. B.; BENSON, G. O. How a corn plant develops. Ames: Iowa State University of Science and Technology, 1993. 26 p. (Special Report, 48).

ROBLES, M. I.; CIMPIATTI, A.; VYN, T. J. Responses of maize hybrids to twin-row spatial arrangement at multiple plant densities. Agronomy Journal, Madison, v. 104, n. 6, p. 1747-1756, 2012.

DOI: 10.2134 /agronj2012.0231.

SANGOI, L.; SCHWITZER, C.; SILVA, P. R. F.; SCHMITT, A.; VARGAS, V. P.; CASA, R. T.; SOUZA, C. A. Perfilhamento, área foliar e produtividade do milho sob diferentes arranjos espaciais. Pesquisa Agropecuária Brasileira, Brasília, DF, v. 46, n. 6, p. 609-616, 2011.

DOI: 10.1590/S0100-204X2011000600006.

SANGOI, L.; ZANIN, C. G.; SCHMITT, A.; VIEIRA, J. Senescência foliar e resposta de híbridos de milho cultivados em diferentes épocas ao adensamento. Revista Brasileira de Milho e Sorgo, Sete Lagoas, v. 12, n. 1, p. 21-32, 2013.

DOI: 10.18512/1980-6477/rbms.v12n1p21-32. 
SANGOI, L.; SILVA, P. R. F. Estratégias de manipulação do arranjo de plantas e desempenho agronômico do milho. In: WORDELL FILHO, J. A.; CHIARADIA, L. A. (Org.). A cultura do milho em Santa Catarina. 3. ed. Florianópolis: Epagri, 2016. v. 1, p. 85-121.

SANTOS, H. G. dos; JACOMINE, P. K. T.; ANJOS, L. H. C. dos; OLIVEIRA, V. A. de; OLIVEIRA, J. B. de; COELHO, M. R.; LUMBRERAS, J. F.; CUNHA, T. J. F. (Ed.). Sistema brasileiro de classificação de solos. 2. ed. Rio de Janeiro: Embrapa Solos, 2006. 306 p.

SERPA, M. S.; SILVA, P. R. F.; SANGOI, L.; VIEIRA, V. M.; MARCHESI, D. R. Densidade de plantas em híbridos de milho semeados no final do inverno em ambientes irrigados e de sequeiro. Pesquisa Agropecuária Brasileira, Brasília, DF, v. 47, n. 4, p. 541-549, 2012. DOI: 10.1590/S0100-204X2012000400010.

SILVA, P. R. F.; PIANA, A. T.; MASS, L.; SERPA, M. S.; SANGOI, L.; VIEIRA, V. M.; ENDRIGO, P. C.; JANDREY, D. B. Adequação da densidade de plantas à época de semeadura em milho irrigado. Revista de Ciências Agroveterinárias, Lages, v. 9, n. 1, p. 48-57, 2010.

STRIEDER, M. L.; SILVA, P. R. F.; ARGENTA, G.; RAMBO, L.; SANGOI, L.; SILVA, A. A.; ENDRIGO, P.
C. A resposta do milho irrigado ao espaçamento entrelinhas depende do híbrido e da densidade de plantas. Ciência Rural, Santa Maria, v. 37, n. 3, p. 634-642, 2007.

DOI: $10.1590 / \mathrm{S} 0103-84782007000300006$.

STRIEDER, M. L.; SILVA, P. R. P.; RAMBO, L.; SANGOI, L.; SILVA, A. A.; ENDRIGO, P. C. Crop management systems and maize grain yield under narrow row spacing. Scientia Agricola, Curitiba, v. 65, n. 4, p. 346-353, 2008.

DOI: $10.1590 / \mathrm{S} 0103-90162008000400004$.

TOLLENAAR, M. Is low plant density a stress in maize? Maydica, Bergamo, v. 37, p. 305-311, 1992.

VARGAS, V. P.; SANGOI, L.; ERANANI, P. R.; SIEGA, E.; CARNIEL, G.; FERREIRA, M. A. Os atributos nas folhas são mais eficientes que o $\mathrm{N}$ mineral no solo para avaliar a disponibilidade deste nutriente para o milho.

Bragantia, Campinas, v. 71, n. 2, p. 21-31, 2012.

DOI: $10.1590 /$ S0006-87052012000200014.

WOLI, K. P.; BURRAS, C. L.; ABENDROTH, L. J.; ELMORE, R. W. Optimizing corn seeding rates using a field's corns suitability rating. Agronomy Journal, Madison, v. 106, n. 4, p. 1523-1532, 2014.

DOI: 10.2134 /agronj14.0054. 